\title{
Image-guided percutaneous removal of intramuscular acupuncture needles using biopsy forceps under computed tomography and fluoroscopy: a report of two cases
}

\author{
Akira Ikoma ${ }^{1}$, Tetsuo Sonomura ${ }^{1}$, Naoaki Shibata ${ }^{2}$, Nozomu Shima ${ }^{1}$, Atsufumi Kamisako ${ }^{1}$, \\ Kodai Fukuda ${ }^{1}$, Nobuyuki Higashino ${ }^{1}$ \\ ${ }^{1}$ Department of Radiology, Wakayama Medical University, Wakayama, Japan; ${ }^{2}$ Department of Emergency and Critical Medicine, Wakayama Medical \\ University, Wakayama, Japan
}

Correspondence to: Akira Ikoma, PhD, MD. Department of Radiology, Wakayama Medical University, 811-1 Kimiidera, Wakayama-shi, Wakayama 641-8509, Japan. Email: yfb04322@nifty.com.

Submitted Nov 02, 2020. Accepted for publication Mar 16, 2021.

doi: 10.21037/qims-20-1228

View this article at: http://dx.doi.org/10.21037/qims-20-1228

\section{Introduction}

Many nonsurgical techniques have been reported for the removal of intravascular foreign bodies. The percutaneous approach is widely perceived as the best technique to retrieve intravascular foreign bodies (1-3). This minimally invasive approach has a high success rate and low morbidity, and it avoids the complications associated with surgical interventions. However, surgical approaches are commonly used to remove intramuscular foreign bodies, and no cases of percutaneous removal of an intramuscular foreign body have been reported. Here, we report two cases of successful image-guided percutaneous removal of intramuscular foreign bodies using biopsy forceps.

\section{Case presentation}

All procedures performed in studies involving human participants were in accordance with the ethical standards of the institutional and/or national research committee(s) and with the Helsinki Declaration (as revised in 2013). Written informed consent was obtained from the patient for publication of this manuscript and any accompanying images.

\section{Case 1}

Case 1 was an 86-year-old woman with right back pain caused by a lost intramuscular acupuncture needle. She was referred to our hospital because of persistent pain. Radiography and computed tomography (CT) of her waist in the prone position showed an embedded acupuncture needle in the right erector muscle of the spine (Figure 1A,B). Therefore, we planned to perform imageguided percutaneous removal of the acupuncture needle using myocardial biopsy forceps.

The patient was placed in the prone position and, under local anesthesia and CT guidance, an 18-gauge needle (Terumo Corporation, Tokyo, Japan) was percutaneously inserted into her right back, close to the acupuncture needle. Next, the inner needle was withdrawn and a 0.035 in guidewire (Surf; Piolax Medical Devices Inc., Kanagawa, Japan) was inserted into the outer needle. The outer needle was withdrawn, and a 6-Fr sheath (Terumo, Tokyo, Japan) was advanced over the guidewire, adjacent to the acupuncture needle. The sheath dilator was replaced with myocardial biopsy forceps (Technowood, Tokyo, Japan), which were used to grasp the acupuncture needle under fluoroscopic guidance (Figure 1C); the system was then retracted en bloc (Figure 1D). CT performed after the procedure confirmed the removal of the intramuscular acupuncture needle. Subsequently, the patient's back pain subsided. No abscess was observed on a follow-up CT acquired 1 month after the procedure. 

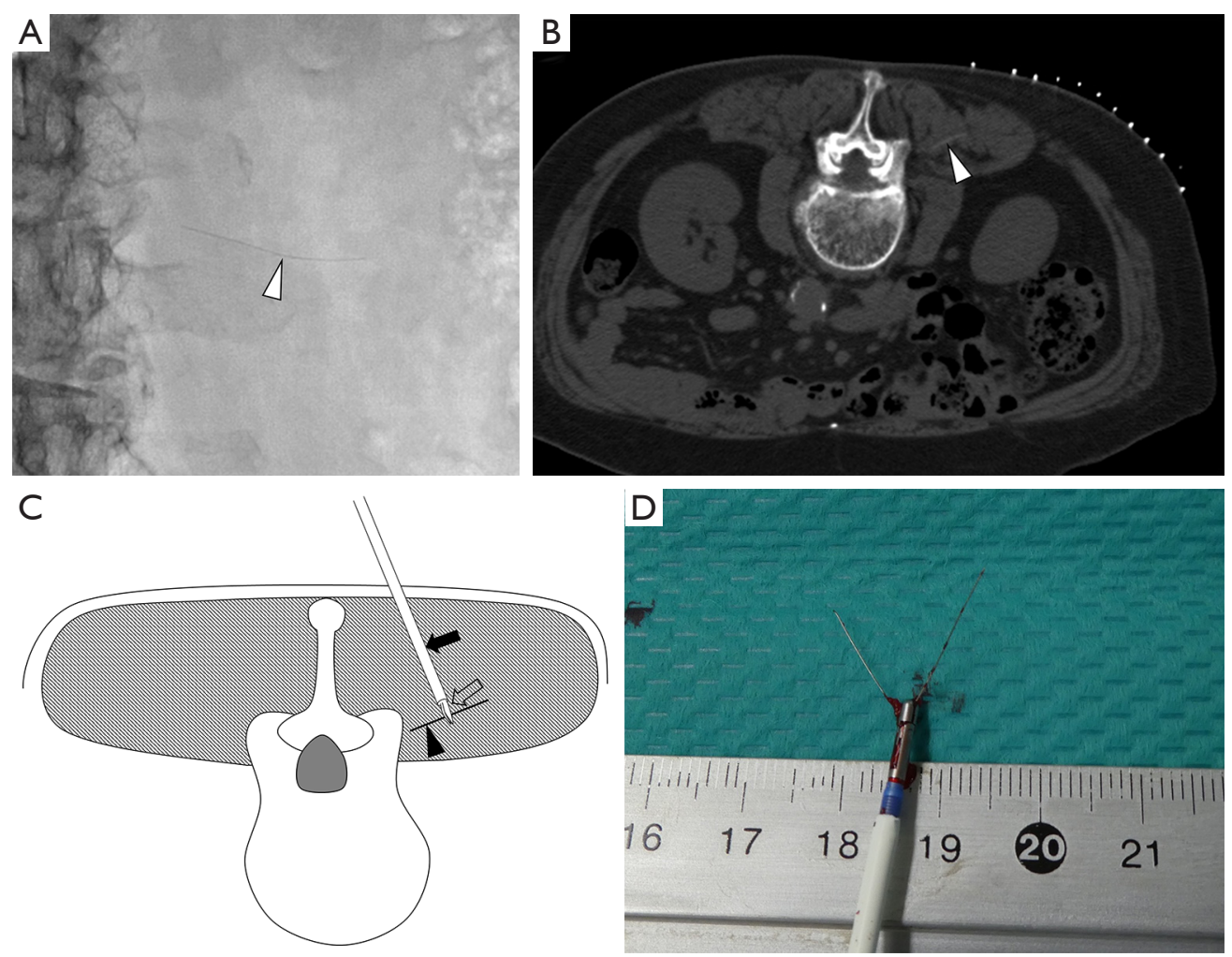

Figure 1 Case 1: an 86-year-old woman with right back pain caused by a lost intramuscular acupuncture needle. (A) Radiograph of the waist shows a paravertebral acupuncture needle (arrowhead). (B) A positioning computed tomography scan was acquired in the prone position. The acupuncture needle (arrowhead) is embedded in the right erector muscle of the spine. (C) Schema showing the acupuncture needle (black arrowhead) grasped by the myocardial biopsy forceps (open arrow) inserted through a 6-Fr sheath (black arrow). (D) Photograph showing en bloc removal of sheath, forceps, and retained acupuncture needle using myocardial biopsy forceps.

\section{Case 2}

Case 2 was a 28-year-old woman with right neck pain resulting from a lost acupuncture needle. Radiography and CT of the neck in the left semi-lateral position showed an embedded acupuncture needle in the right erector muscle of the spine (Figure 2A,B). She was referred to our department for nonsurgical removal of the acupuncture needle.

With the patient placed in the left semi-lateral position under local anesthesia, we approached the acupuncture needle (Figure 2C), as in Case 1. Using the aforementioned technique, we grasped the acupuncture needle using the biopsy forceps under fluoroscopic guidance (Figure 2D), and retracted the system en bloc. CT confirmed the successful removal of the acupuncture needle by the procedure. There were no post-procedure complications and the patient left the hospital immediately after the procedure. Her neck pain resolved shortly thereafter.

\section{Discussion}

Many reports have described percutaneous removal of intravascular foreign bodies. Interventional Radiologists all over the world try different techniques in clinical practice to retrieve non-intravascular foreign bodies. Nosher et al. reported six cases in which percutaneous technique was used for removal of non-intravascular foreign bodies. Those foreign bodies included an intraabdominal laparotomy towel, two pelvic drains, an angiographic guidewire fragment in a pelvic abscess cavity, a superficially located sewing needle, and a bullet fragment (4). However, there are few reported cases of percutaneous removal of intramuscular foreign bodies. Salsamendi et al. (5) reported the removal of an intramuscular contraceptive implant in the biceps brachii muscle. Although those authors advanced an Amplatz guidewire beneath the implant under ultrasonographic guidance, to render it palpable, they 

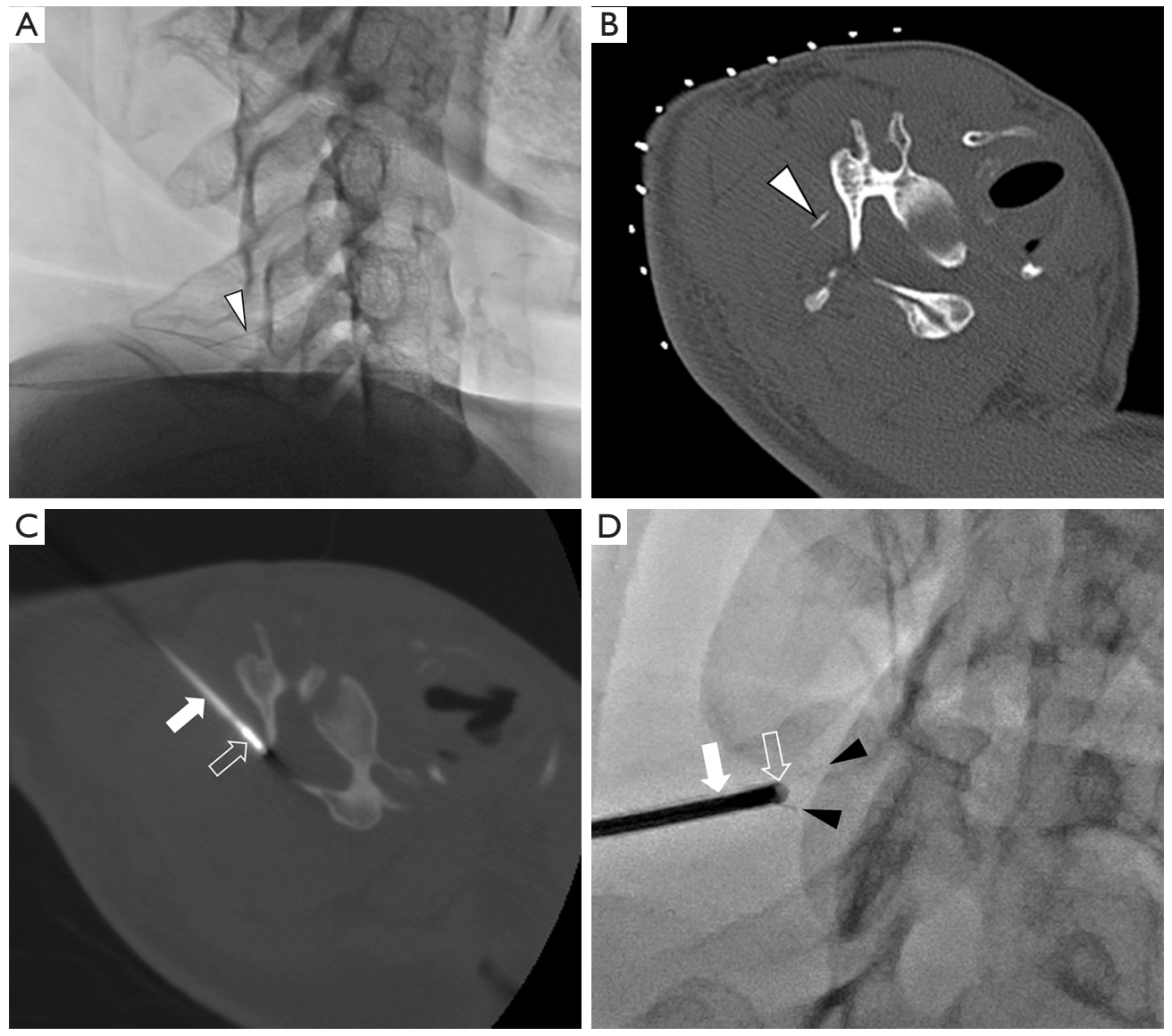

Figure 2 Case 2: a 27-year-old woman with right neck pain resulting from a lost acupuncture needle. (A) Radiograph of the neck showing a paravertebral acupuncture needle (arrowhead). (B) A positioning computed tomography scan acquired in the left semi-lateral position shows the acupuncture needle (arrowhead) embedded in the right erector muscle of the spine. (C) Computed tomography scan showing the myocardial biopsy forceps (open arrow) inserted through a 6 Fr sheath (arrow). (D) Fluoroscopic image showing the acupuncture needle (arrowheads) grasped by the myocardial biopsy forceps (open arrow) inserted through a 6-Fr sheath (arrow).

made a small skin incision and freed the implant from the surrounding tissues by blunt dissection, to remove it.

We selected myocardial biopsy forceps, because it was too difficult to use loop snare techniques $(6,7)$ for removal of intramuscular acupuncture needles. The advantage of using forceps is that unlike snares, they do not require free end of the foreign body (2). However, forceps may cause muscle damage or hemorrhage, and removing a foreign body using these forceps is an off-label use. Furthermore, because the head of the catheter is small, its grasping ability may be restricted and its use is limited to the retrieval of foreign objects with a small diameter (8).

The major challenge of this procedure was precise localization of the intramuscular foreign body to minimize dissection of the surrounding soft tissues (4). This was achieved by moving the sheath close to the intramuscular foreign body using a combination of CT and fluoroscopy.

\section{Conclusions}

In these cases, we successfully removed retained acupuncture needles embedded in the erector muscles of the spine using myocardial biopsy forceps under CT and fluoroscopic guidance. To the best of our knowledge, this is the first report to describe image-guided percutaneous removal of intramuscular foreign bodies.

\section{Acknowledgments}

Funding: None. 


\section{Footnote}

Conflicts of Interest: All authors have completed the ICMJE uniform disclosure form (available at http://dx.doi. org/10.21037/qims-20-1228). The authors have no conflicts of interest to declare.

Ethical Statement: The authors are accountable for all aspects of the work in ensuring that questions related to the accuracy or integrity of any part of the work are appropriately investigated and resolved. All procedures performed in studies involving human participants were in accordance with the ethical standards of the institutional and/or national research committee(s) and with the Helsinki Declaration (as revised in 2013). Written informed consent was obtained from the patient for publication of this manuscript and any accompanying images.

Open Access Statement: This is an Open Access article distributed in accordance with the Creative Commons Attribution-NonCommercial-NoDerivs 4.0 International License (CC BY-NC-ND 4.0), which permits the noncommercial replication and distribution of the article with the strict proviso that no changes or edits are made and the original work is properly cited (including links to both the formal publication through the relevant DOI and the license). See: https://creativecommons.org/licenses/by-ncnd $/ 4.0 \%$.

Cite this article as: Ikoma A, Sonomura T, Shibata N, Shima N, Kamisako A, Fukuda K, Higashino N. Imageguided percutaneous removal of intramuscular acupuncture needles using biopsy forceps under computed tomography and fluoroscopy: a report of two cases. Quant Imaging Med Surg 2021;11(9):4227-4230. doi: 10.21037/qims-20-1228

\section{References}

1. Woodhouse JB, Uberoi R. Techniques for intravascular foreign body retrieval. Cardiovasc Intervent Radiol 2013;36:888-97.

2. Floridi C, Nocchi-Cardim L, De Chiara M, Ierardi AM, Carrafiello G. Intravascular foreign bodies: what the radiologist needs to know. Semin Ultrasound CT MR 2015;36:73-9.

3. Rodrigues R, Agostinho A, Anacleto G, Branco P, Gonçalves Ó. Endovascular Removal of Foreign Bodies. Rev Port Cir Cardiotorac Vasc 2017;24:109.

4. Nosher JL, Siegel R. Percutaneous retrieval of nonvascular foreign bodies. Radiology 1993;187:649-51.

5. Salsamendi JT, Morffi D, Gortes FJ. Removal of an Intramuscular Contraceptive Implant. J Vasc Interv Radiol 2017;28:465.

6. Cekirge S, Weiss JP, Foster RG, Neiman HL, McLean GK. Percutaneous retrieval of foreign bodies: experience with the nitinol Goose Neck snare. J Vasc Interv Radiol 1993;4:805-10.

7. Wolf F, Schernthaner RE, Dirisamer A, Schoder M, Funovics M, Kettenbach J, Langenberger H, Stadler A, Loewe C, Lammer J, Cejna M. Endovascular management of lost or misplaced intravascular objects: experiences of 12 years. Cardiovasc Intervent Radiol 2008;31:563-8.

8. Fisher RG, Ferreyro R. Evaluation of current techniques for nonsurgical removal of intravascular iatrogenic foreign bodies. AJR Am J Roentgenol 1978;130:541-8. 